\title{
Evaluación de riesgos ambientales del distrito de Morococha
}

\section{Environmental risk assessment district of Morococha}

\author{
Guerreros Meza, Manuel ' / Rupay Guere, Felipe ${ }^{2}$ \\ 1manuelguerreros@yahoo.com \\ 2frupayg@hotmail.com \\ Facultad de Ingeniería Metalúrgica, Universidad Nacional del Centro del Perú
}

\section{RESUMEN}

En la investigación se realizó el estudio del recurso agua y se determinó que está siendo contaminada por los valores de $\mathrm{pH}$ detectados fuera de los límites máximos permisibles y los sólidos totalmente disueltos generados por la actividad minera y los pasivos ambientales en el distrito de Morococha.

Palabras clave: contaminación, pasivos ambientales.

\begin{abstract}
In the research the study of water resources was conducted and it was determined that this being polluted by the $\mathrm{pH}$ values detected outside of the maximum permissible limits and total dissolved solids generated by mining and environmental liabilities in the district of Morococha.
\end{abstract}

Keywords: pollution, environmental liabilities. 


\section{INTRODUCCIÓN}

La actividad metalúrgica es de vital importancia para el desarrollo económico de una sociedad. En el Distrito de Morococha se continua desarrollando la actividad minera, y debido a la existencia de activos y pasivos no se identifica la fuente que origina los problemas de contaminación ambiental, que afecta a la salud de la población y del ambiente, pero su continuo uso ha estado afectando la ganadería y a la población debido al incremento de la contaminación ambiental de la zona generada por los procesos metalúrgicos como es la concentración de minerales que se desarrolla por las plantas concentradoras en esta zona minera.

El objetivo principal de la investigación es determinar si el recurso agua está siendo contamina- da en el distrito de Morococha.

\section{MARCO TEÓRICO}

Impactos ambientales en las operaciones mineras

Los recursos minerales, como parte de los recursos naturales, se integran en el propio sistema multidimensional que configura el medio ambiente.

El ser humano mediante la extracción de los recursos naturales y transformación posterior en productos y/ o residuos introduce lo que se denomina el medio ambiente transformado y cuya incidencia puede haberse concretado sobre el medio físico, químico, biótico y social.

\section{Límites máximos permisibles}

Tabla 1. Límites máximos permisibles para la descarga de efluentes líquidos de actividades minero - metalúrgicas

\begin{tabular}{llcc}
\hline \multicolumn{1}{c}{ Parámetro } & Unidad & $\begin{array}{c}\text { Límite en cualquier } \\
\text { momento }\end{array}$ & $\begin{array}{c}\text { Límite para el } \\
\text { promedio anual }\end{array}$ \\
\hline $\mathrm{pH}$ & & $6-9$ & $6-9$ \\
Sólidos Totales en Suspensión & $\mathrm{mg} / \mathrm{L}$ & 50 & 25 \\
Aceites y Grasas & $\mathrm{mg} / \mathrm{L}$ & 20 & 16 \\
Cianuro Total & $\mathrm{mg} / \mathrm{L}$ & 1 & 0,8 \\
Arsénico Total & $\mathrm{mg} / \mathrm{L}$ & 0.1 & 0.08 \\
Cadmino Total & $\mathrm{mg} / \mathrm{L}$ & 0,05 & 0.04 \\
Cromo Hexavalente $\left(^{*}\right)$ & $\mathrm{mg} / \mathrm{L}$ & 0.1 & 0,08 \\
Cobre Total & $\mathrm{mg} / \mathrm{L}$ & 0.5 & 0.4 \\
Hierro (Disuelto) & $\mathrm{mg} / \mathrm{L}$ & 2 & 1.6 \\
Plomo Total & $\mathrm{mg} / \mathrm{L}$ & 0.2 & 0.16 \\
Mercurio Total & $\mathrm{mg} / \mathrm{L}$ & 0.002 & 0.0016 \\
Zinc Total & $\mathrm{mg} / \mathrm{L}$ & 1.5 & 1.2 \\
\hline
\end{tabular}

\section{MATERIALES Y MÉTODOS}

\section{MATERIALES:}

$\checkmark$ Equipos de muestreo

$\checkmark \quad$ Equipo de análisis químico

$\checkmark$ Materiales de laboratorio

MÉTODO DE INVESTIGACIÓN.- Método experimental.

TIPO DE INVESTIGACIÓN.- Investigación aplicada. 


\section{RESULTADOS:}

Tabla 2.

\begin{tabular}{cl}
$\begin{array}{c}\text { Puntos de } \\
\text { Muestreo }\end{array}$ & \multicolumn{1}{c}{$\begin{array}{c}\text { Estaciones de Monitoreo Ambiental: Recurso Agua } \\
\text { Ubicación }\end{array}$} \\
\hline & \multicolumn{1}{c}{ CUENCA RIO PACHACHACA } \\
$M-1$ & Laguna Huacracocha \\
$M-2$ & Laguna Churruca \\
$M-3$ & Estanque de Agua Laguna Churruca \\
$M-4$ & Superficie de la Relavera Antigua Morococha-Centromin \\
$M-5$ & Canal de Coronación de Relavera Antigua \\
$M-6$ & Salida de Laguna Huascacocha \\
& $\quad$ CUENCA RIO YAULI \\
$M-7$ & Puente Cut Off, frentea las instalaciones de la Planta Calera Cut Off. \\
\hline
\end{tabular}

Tabla 3.

\begin{tabular}{|c|c|c|c|c|c|c|c|}
\hline \multirow{3}{*}{ PARAMETROS } & \multicolumn{7}{|c|}{ MUESTRA } \\
\hline & \multicolumn{6}{|c|}{ RIO PACHACHACA } & \multirow{2}{*}{$\frac{\text { RIO YAULI }}{M-7}$} \\
\hline & $M-1$ & $M-2$ & $M-3$ & $M-4$ & $M-5$ & $M-6$ & \\
\hline $\mathrm{pH}$ & 6.55 & 3.52 & 3.6 & 2.72 & 6.72 & 6.6 & 6.5 \\
\hline $\begin{array}{c}\text { Sólidos Totales } \\
\text { Suspendidos - STS (mg/l) }\end{array}$ & 199 & 325 & 180 & ND & 209 & 226 & 531 \\
\hline Cobre - Cu (mg/l) & ND & ND & ND & ND & ND & 0 & ND \\
\hline Hierro - Fe (mg/l) & ND & ND & ND & ND & ND & 0.33 & ND \\
\hline Plomo - Pb (mg/l) & ND & ND & ND & ND & ND & 2.46 & ND \\
\hline Cadmio - Cd (mg/l) & ND & ND & ND & ND & ND & 0.75 & ND \\
\hline $\begin{array}{c}\text { Conductividad m } \\
\mathrm{s} / \mathrm{cm}\end{array}$ & 380 & 950 & 900 & 373 & 440 & 880 & 830 \\
\hline
\end{tabular}

\section{DISCUSIÓN}

- A partir de los estudios y las evaluaciones realizadas se determina que el recurso agua está siendo contaminado en lo que se refiere a $\mathrm{pH}$ y solidos totalmente disueltos.

\section{CONCLUSIONES}

- A partir de los estudios y las evaluaciones realizadas el recurso agua está siendo afectada al haberse encontrado el $\mathrm{pH}$ con valores de $3.52,3.6$ y 2.72 en los puntos M-2, M-3 y M-4 respectivamente.

- De la Evaluación realizada en el recurso agua también se encontró valores para TSS de 199, 325, 180, 209, 226 y 531 en los puntos: $M-1, M-2, M-3$ y $M-5, M-6$ y $M-7$ respectivamente.

- Por lo tanto deducimos que se encontró contaminado el recurso agua bajo la normatividad vigente. 


\section{RECOMENDACIONES}

- Amerita realizar una permanente Vigilancia y fiscalización por parte de la OEFA a las empresas mineras del entorno del distrito de Morococha, puesto que la población, el ambiente y las actividades socioeconómicas están siendo afectadas moderadamente.

\section{REFERENCIAS BIBLIOGRÁFICAS}

1. Brack Egg. (2000). Ecología del Perú, Programa de las Naciones Unidas para el Desarrollo, Perú, $1^{\circ}$ ed. Lima: Editorial Bruño.

2. Canter Larry W. (1998). Manual de Evaluación de Impacto Ambiental. $2^{\circ}$ ed. Washington: Mac Graw Hill.

3. Vásquez Absalon. (1994). El Riego. $1^{\circ} \mathrm{ed}$. Lima: Editorial La Molina.

4. Audesirk, T. Audesirk. (2003). Biología: la vida en la tierra. $6^{\circ}$ ed. Madrid: Prentice Hall.

5. Solomon Villee. (2001). Biología. 5a ed. México: Interamericana. 